Resenhas 


\section{Anton Bruckner, o Bach do romantismo}

Luiz Paulo Horta

L AUro Machado Coelho é crítico musical de $O$ Estado de S. Paulo. De alguns anos para cá, ele vinha nos oferecendo estudos alentados sobre ópera “A ópera francesa”, “A ópera alemã”, "A ópera russa” etc. Como se isso não bastasse, ele engrena agora uma série de biografias de que resultaram, em rápida sucessão, estudos sobre Liszt, Berlioz, Sibelius, Bruckner. Só pelo volume de trabalho, já seria notável. Mas, em cada um desses ensaios, notam-se também capacidade analítica e verve estilística.

O menestrel de Deus - vida e obra de Anton Bruckner tem um atrativo especial: ao que eu saiba, é o primeiro estudo sobre Bruckner em português. E chega com perfeito senso de timing. Porque Bruckner, de maneira surpreendente, é um compositor "na moda". Ele não conheceu isso em vida - uma vida que ocupa o miolo do movimento romântico (1824-1896). Teve um ou outro raro sucesso na Viena que dava a Brahms o primeiro lugar entre os músicos. Foi cruelmente perseguido pelo maior crítico da época - Hanslick. Era desajeitado, e conservou por toda a vida um certo ar "caipira", com suas roupas excêntricas. Mas esse eterno "gauche" teve seguidores dedicadíssimos - como Gustav Mahler; e, de repente, depois de décadas de negligência, ele está em todos os programas, é destaque no Festival de Salzburgo.

Mistério do gosto e das modas. Porque ele não faz concessões. É um músico interiorizado, que parece estar sempre em contato com regiões superiores. Suas sinfonias, enormes, foram comparadas, pelo severo Brahms, a jiboias. Atormen- tado pelas críticas, ele tentou, em seus últimos anos, revisões drásticas nas partituras - o que não fez bem aos originais. Por conta disso, um maestro que queira reger Bruckner precisa escolher entre diferentes edições. Muitas vezes, o mais certo e o mais seguro é voltar ao original.

Anton Bruckner nasceu nas montanhas da Áustria em 1824. É, assim, um pouco mais moço que a grande geração romântica (Chopin, 1810; Schumann, 1810; Liszt, 1811; Verdi, 1813; Wagner, 1813), e uns dez anos mais velho do que Brahms, que era de 1833. Ele se coloca, assim, no miolo do movimento romântico, sendo ele mesmo um grande romântico (veja-se o início da Sinfonia n.2). Mas a sua arte é intensamente pessoal - única, mesmo -, e é injusto dizer que ele é um epígono de Wagner (seu ídolo incontrastável).

A música de Bruckner é grandiosa e, ao mesmo tempo, lírica. Existe um "som" Bruckner, assim como existe um som Mahler. Ele faz um uso poderoso e expressivo dos metais. Mas também sabe fazer as cordas cantarem, em melodias longas e emocionadas. Nasceu numa cidadezinha chamada Ansfelden, mas sua célula mater foi a cidade de Linz, que tem o triste privilégio de ser a terra natal de Hitler. A Áustria, naquele momento, vivia sob a férula do chanceler Metternich e a autoridade absoluta do Kaiser Franz Joseph. Em compensação, para o jovem Bruckner, havia a música de igreja, na tradição de Haydn e Mozart, que ele ia enriquecer, um dia, com quatro grandes missas, "pendant” das suas nove sin- 
fonias. Acabados os primeiros estudos, ele sucedeu ao pai como mestre-escola, e levaria muitos anos até aventurar-se na atmosfera cosmopolita de Viena.

Pode-se dizer que fez música desde menino. Mas suas primeiras emoções fortes vieram da frequentação do mosteiro agostiniano de Sankt Florian, com seu magnífico órgão e sua majestosa arquitetura barroca. Em Sankt Florian, ele foi aceito como menino de coro - tal como acontecera com Schubert. E por toda a vida ele procuraria o mosteiro como um refúgio em tempos difíceis. Tudo isso faz dele uma espécie de Bach do romantismo: na sua obra madura, é a mesma elevação de pensamento, e a presença do transcendente.

Outra aproximação com Bach: o órgão, que ele começou a tocar aos 14 anos, e em que seria o maior improvisador do seu tempo (visitas memoráveis a Londres e a Paris confirmaram essa opinião). O primeiro momento importante na sua trajetória de criador é um Réquiem em ré menor escrito em 1849. Haydn e Mozart ainda são os seus modelos - em especial o Réquiem de Mozart. Mas já se vê, ali, uma gravidade, uma majestade que anunciam o Bruckner maduro. E sente-se muitas vezes o órgão por trás da sua música instrumental. Como escreveu o seu biógrafo Gollerich,

a estatura posterior de Bruckner como sinfonista só pode ser plenamente compreendida se voltarmos a essa época de crescimento e amadurecimento no grande órgão de Sankt Florian. Seu ardor juvenil e sua imaginação foram estimulados pelas obras de arte do culto católico, com a sua esplêndida arquitetura, pinturas e vestimentas suntuosas, nuvens narcóticas de incenso, canto majestoso, e o órgão tocando a plenos pulmões.

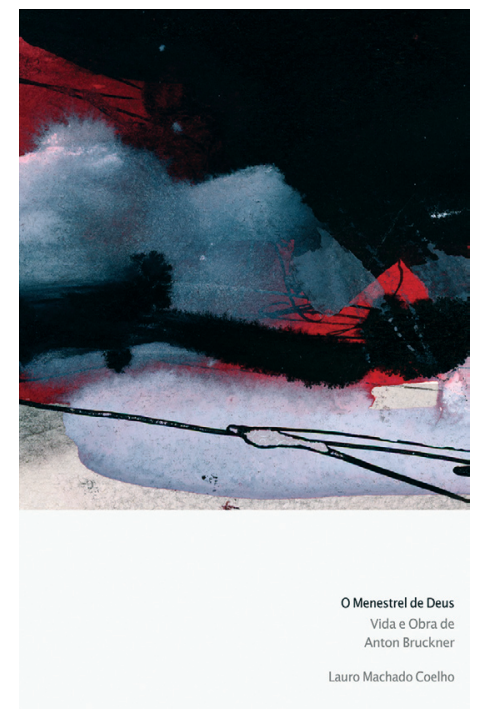

COELHO, Lauro Machado. O menestrel de Deus - vida e obra de Anton Bruckner. São Paulo: Algol, 2009. 248p.

Chegou o momento em que Sankt Florian já não o satisfaz. Ele se torna, por concurso, organista em Linz, a grande cidade das vizinhanças. Tinha 32 anos. Seguiram-se 12 anos de trabalhos árduos, em que Bruckner compôs pouco, mas que lançaram os fundamentos da sua obra de sinfonista.

Ele era um estudante obsessivo, nunca achava que estava pronto. Um caso típico de "late developer". Mas também havia ali uma espécie de mania, que o fazia passar até sete horas por dia enchendo cadernos de exercícios, que ele enviava a um professor importante, Sechter. Depois de receber, no mesmo dia, 17 cadernos, Sechter escreveu-lhe: "Devo realmente implorar-lhe que tome mais cuidado consigo mesmo, dando-se tempo suficiente para descansar".

Solteiro, Bruckner queria casar-se, mas insistia em fazer a corte a meninas mal saídas da adolescência, que rejeitavam o mestre desajeitado, com seus 


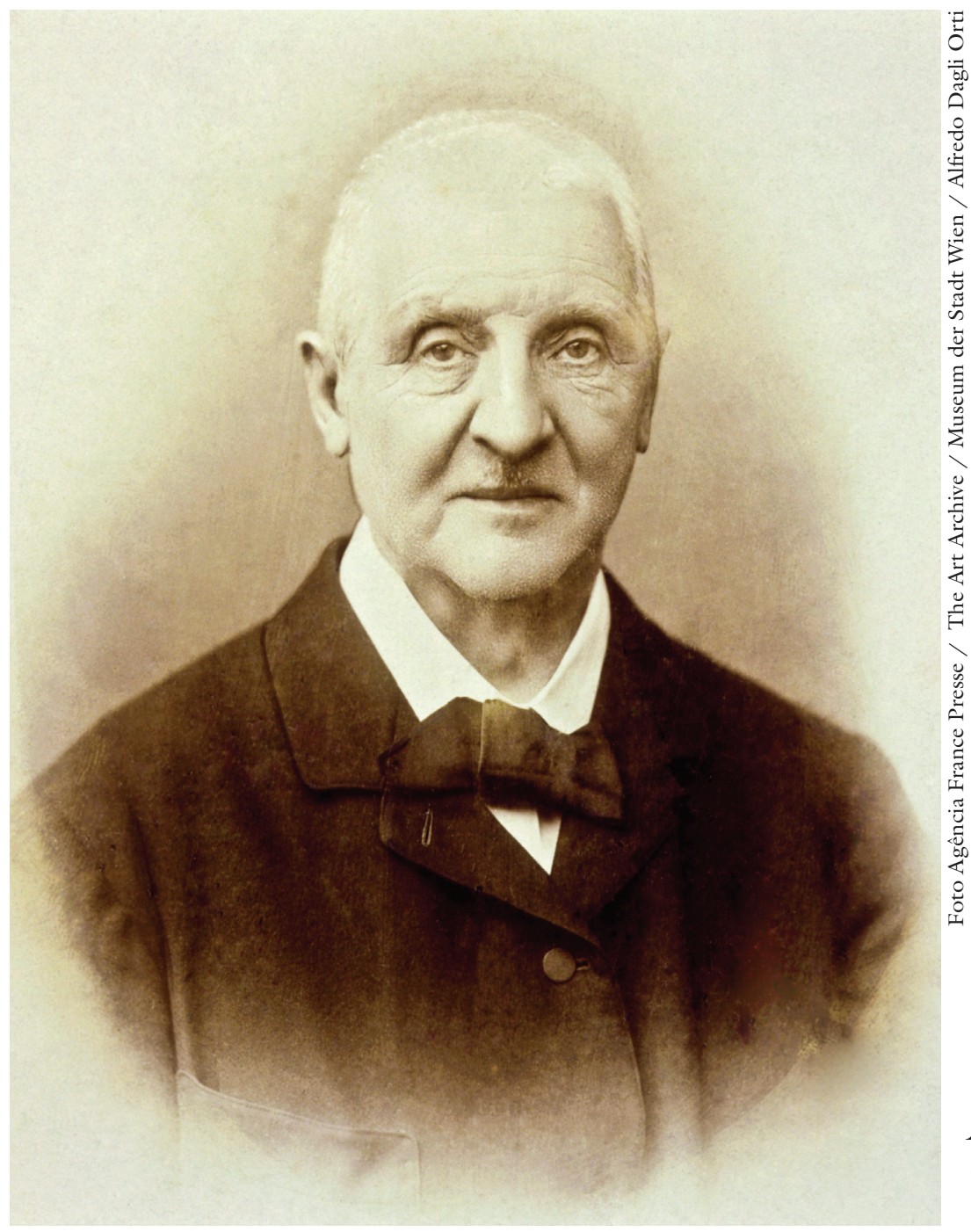

tiques de personalidade. A essa altura, acontecem dois enormes impactos em sua sensibilidade de artista: a obra de Wagner e a Nona Sinfonia de Beethoven. A devoção a Wagner assumiria um caráter quase religioso, o que não o ajudaria em seus anos de Viena. A capital austríaca dividia-se em adeptos de Brahms e de Wagner, e o principal crítico de Viena, Hanslick, fez Bruckner pagar caro por sua dedicação a Wagner.

Excesso de trabalho, medo do futuro, ansiedade por não ser reconhecido como artista, tudo isso levou Bruckner, em 1867, a um esgotamento nervoso e à internação num sanatório. Sua estrutura psíquica revelava pontos fracos. Ele sofria de crises de depressão, de ideias fixas. Tinha cacoetes obsessivos, como contar as folhas de uma árvore ou o número de barras de uma cerca. Mas o milagre do gênio supera esses obstáculos.

Ele estava então decidido a mudar-se para Viena, o que afinal conseguiu em 1868. Instalou-se na capital com sua irmã Nani, tendo arranjado um cargo de professor na Gesellschaft der Musikfreunde. Encontrava uma cidade imponente, que o Kaiser resolvera modernizar, substituindo as velhas fortificações 
pelo famoso Ring - larga avenida que segue o contorno das antigas muralhas. Mas a importância política do império diminuíra, desde que Bismarck resolvera levar adiante o projeto de hegemonia prussiana na Confederação germânica.

Viena compensava sua perda de importância política com uma "joie de $v i$ vre" cada vez maior - e uma velha paixão pela música. Brahms era o grande nome, continuador da tradição beethoveniana. Bruckner fazia figura de excêntrico. Suas primeiras sinfonias não foram insucessos; mas logo ele estava debaixo da marcação cerrada de Hanslick, em razão de seu suposto wagnerismo. E essa pressão não o abandonaria nunca, a ponto de ele pedir ao Kaiser, numa ocasião em que foi premiado, que fizesse Hanslick persegui-lo menos!

E com tudo isso, ele abriu seu caminho para os píncaros orquestrais que são as sinfonias 5, 6, 7, 8 e 9. Para alguns, o gênero sinfônico estaria em crise quando Bruckner engrena a sua sucessão de obras-primas. Também se disse isso da sonata, depois de Beethoven. Otto Maria Carpeaux, normalmente tão arguto, chegou a negar validade às últimas sonatas de Schubert, dizendo que elas só podiam interessar a "pianistas ambiciosos”. Sabemos hoje que não é assim. E pode-se tentar uma aproximação entre Schubert e Bruckner.

Nos dois, tem-se uma inspiração melódica puríssima que lembra o ar das montanhas da Áustria. Mas, o que é mais importante, sonatas de Schubert e sinfonias de Bruckner não podem ser avaliadas pelos padrões da forma clássica.

A forma sonata que Beethoven recebeu de Haydn e Mozart oferece uma oportunidade admirável para a arquitetura sonora. É uma forma tripartite: ex- posição, desenvolvimento, reexposição, a que costuma juntar-se uma coda. Isso pode ser visto com nitidez numa obra como a Quinta Sinfonia de Beethoven. Também se poderia aplicar essa visão a uma sinfonia de Brahms. Em todos esses casos, é convincente a lógica arquitetônica. Vemos uma estrutura que tem $\mathrm{co}^{-}$ meço, meio e fim, e que atende às necessidades de um princípio dramático: criar tensão para depois resolvê-la.

Nada disso tem a mesma importância se analisamos algumas obras de Schubert, e o conjunto da produção de Bruckner. É preciso deixar de lado a tirania da lógica. Em vez disso, temos um passeio musical que pode tomar direções inesperadas (característica de Bruckner é a maneira como a música, de repente, parece parar, e perguntamos: o que vem agora?). Para ouvir essas peças, é preciso abrir mão de um roteiro previsível. É melhor pensar que estamos numa vereda de montanha, com os seus meandros (o que não significa dizer que não exista um sentido de direção).

No caso de Bruckner, também é possível um paralelo com a arte de Bach. Desta vez, não pelo lado estrutural (sendo Bach um dos grandes "construtores” da história da música), mas pela conexão quase direta com uma experiência transcendente. Nesse sentido, seria possível adotar o paralelismo Mahler/ Beethoven, Bruckner/Bach. Sendo a primeira uma dupla de Prometeus, essencialmente comprometida com a terra, com as concretudes (e amarguras) da experiência humana (o que não exclui, claro, escapadas "transcendentes" em Mahler e em Beethoven). Já em Bruckner e em Bach, a terra não se mostra tão presente. É como se o espírito facilmente se desligasse das realidades “daqui” para 
empreender voos que nos conduzem diretamente ao inefável.

Uma das várias injustiças que se cometeram com Bruckner foi a de levar longe demais a ideia da influência avassaladora de Wagner. A influência, de fato, foi enorme. Na Primeira Sinfonia, o clima wagneriano está presente. Mas nem nessa primeira tentativa Bruckner é um simples epígono.

Outro equívoco é achar que ele é um ingênuo sempre pronto a utilizar a plena força da orquestra. Ledo engano, que também se cometeu com Mahler. A exuberância sonora, em Bruckner, aparece em momentos absolutamente característicos, quando ela é uma necessidade incontornável da "maneira" do compositor. E, embarcando nessa viagem oferecida por qualquer das sinfonias de Bruckner, tanto podemos encontrar a orgia do som (a música levada a um apogeu de grandiosidade) como podemos ser conduzidos a meandros secretos, a verdadeiros trechos de música de câmara, de uma delicadeza total.

Escreve Lauro Machado Coelho:

Todas as sinfonias começam de forma mais ou menos nebulosa e envolta em mistério - o que não deixa de ser uma homenagem à Nona de Beethoven. Desse pano de fundo misterioso emergem temas que são a proclamação de harmonias fundamentais - do que um místico como Eckhardt chamaria de "grund" (ground). Derek Watson chama a atenção para o fato de que nenhum desses inícios lembra o prelúdio do "Ouro do Reno", embora compartilhem com ele a sensação de que estamos assistindo à criação do mundo, como é o caso, por exemplo, da Sinfonia n.4.

A enorme profundidade emocional dos primeiros movimentos e dos adágios é caracteristicamente compensada pela vivacidade dos scherzos, que podiam ser danças camponesas magnificadas - mas que também podem assumir aspectos trágicos no Bruckner da Nona Sinfonia.

Lauro diz que nos scherzos encontrase a identidade austríaca de Bruckner. Temos aqui uma forma ABA - isto é, um primeiro grupo de temas seguido de material novo e da volta à temática inicial. Em música clássica, chama-se Trio a parte central dos scherzos. E nesses trios, Bruckner utiliza sem cerimônia o estilo dos "landler", que Schubert também usou: formas ternárias, mais rústicas do que uma valsa. (Mahler seguiria o mesmo caminho nos seus scherzos.)

Uma boa conclusão para a arte transcendente de Bruckner pode ser encontrada em The essence of Bruckner, de Robert Simpson, que escreve:

A essência da música de Bruckner, acredito, está na paciente busca do apaziguamento. Isto não significa um desejo místico de paz. Ao falar em apaziguamento, quero referir-me à tendência de Bruckner de remover, um a um, todos os elementos perturbadores ou dispersivos até revelar um último estrato de pensamento calmamente contemplativo. A suprema realização desse modelo é a Oitava Sinfonia, na qual cada movimento parece preparar o seguinte. Passando a tempestuosa turbulência do Allegro inicial, percebemos toda a energia que há no Scherzo; e quando ele se extingue, o Adágio nos faz lentamente descobrir o sereno e poderoso Finale. De um modo geral, em Bruckner, as tensões humanas são gradualmente pacificadas, e este é um processo positivo, não negativo: elas são equilibradas, dirigidas e fortalecidas no Finale da Oitava; e, neste sentido, Bruckner difere radicalmente do tipo 
de romântico que libera suas tensões em vez de acalmá-las.

Eu diria que isso vem do fato de que Bruckner está firmemente ancorado naquele "grund" que é como o reflexo invertido da transcendência - o que está por baixo de toda a experiência humana, ao mesmo tempo que sugere as maiores alturas.

Luiz Paulo Horta é jornalista e crítico musical. Dirigiu a publicação do Dicionário de música Zahar e a edição brasileira do Grove Dictionary of Music and Musicians. É autor de diversos livros sobre música, como Caderno de música, Guia da música clássica em CD, Villa Lobos: uma introdução e Sete noites com os clássicos. É membro da Academia Brasileira de Letras (ABL). @- luiz.horta@globo.com.br 